ROYO, Manuela: "Libertad religiosa y pluralismo cultural: nuevos desafíos del derecho penitenciario".

Polít. Crim. Vol. 15, No 29 (Julio 2020), Art. 9, pp. 259-289

[http://politcrim.com/wp-content/uploads/2020/07/Vol15N29A9.pdf]

\title{
Libertad religiosa y pluralismo cultural: nuevos desafíos del derecho penitenciario
}

\section{Religious freedom and cultural pluralism: new challenges in the prison law}

\author{
Manuela Royo Letelier \\ Doctora ( $)$ en Derecho, Universidad de Talca \\ Profesora de Derecho Internacional Público, Facultad de Derecho, Universidad Andrés \\ Bello. \\ Dirección postal: Bellavista 0121, Providencia, Santiago. \\ Dirección electrónica: royo.manuela@gmail.com
}

\section{Resumen}

Este artículo indaga los alcances y el contenido del derecho a la libertad religiosa en el derecho internacional de los derechos humanos, y su aplicación concreta en el caso de las personas indígenas privadas de libertad. Para ello, analiza la relación entre la reglamentación de la actividad penitenciaria y los derechos fundamentales de las personas privadas de libertad, para abordar las problemáticas asociadas a la interpretación de los derechos religiosos en ámbitos multiculturales. En este contexto, esta investigación describe la historia del sistema carcelario chileno y la construcción de un sistema penitenciario occidental, constatando la proyección de este sistema colonial en la regulación penitenciaria actual, analizando diversos casos de connotación pública en la materia, para finalmente construir una propuesta de modificación de la regulación penitenciaria acorde con los estándares internacionales en la materia.

Palabras clave: Derecho Penitenciario, libertad de culto, pluralismo, pueblos indígenas

\begin{abstract}
This article explores the scope and content of the right to religious freedom in the international human rights law, and its concrete application in the case of imprisoned indigenous people. To do achieve this goal, the article analyzes the relationship between prison regulation and fundamental rights to address the problems associated with the interpretation of religious and multicultural rights. In this context, this article describes the history of the Chilean prison system and the construction of the western penitentiary system, identifying the projection of the colonial system in the current penitentiary analyzing several high profile cases. Finally, this article propose a modification of the prison law based on international standards.
\end{abstract}

Keywords: Prison Law, freedom of religion, pluralism, indigenous people. 


\section{Polít. Crim. Vol. 15, № 29 (Julio 2020), Art. 9, pp. 259-289 \\ [http://politcrim.com/wp-content/uploads/2020/07/Vol15N29A9.pdf]}

\section{Introducción}

Para el derecho internacional, la consideración de la cultura es uno de los elementos que los Estados deben al momento de establecer y/o aplicar políticas públicas, dado que el origen étnico ${ }^{1}$ de las personas es una categoría protegida por el Pacto de San José de Costa Rica en su artículo $1.1,{ }^{2}$ que incluye categorías prohibidas de discriminación, entre las que se encuentra el origen étnico. En consecuencia, la propia Corte Interamericana de Derechos Humanos ha definido que "ninguna norma, decisión o práctica de derecho interno, sea por parte de autoridades estatales o por particulares, pueden disminuir o restringir, de modo alguno, los derechos de una persona a partir de su origen étnico". ${ }^{3}$

Las personas indígenas privadas de libertad se encuentran dentro de lo que las Reglas Mínimas de las Naciones Unidas para el Tratamiento de los Reclusos, ${ }^{4}$ han considerado como grupos vulnerables, y por lo tanto, sujetos de especial protección. Sin embargo, existe una brecha de implementación entre lo que los estándares de Derechos Humanos en la materia refieren y su aplicación. Muestra de ello, el Estudio de las Condiciones Carcelarias en Chile, realizado por el Instituto Nacional de Derechos Humanos durante los años 2016 y 2017, logró evaluar el estado de cumplimiento de los estándares internacionales de Derechos Humanos en materia de personas privadas de libertad, concluyendo en el apartado acerca derechos culturales de las personas indígenas privadas de libertad que: "La población indígena se encuentra invisibilizada y no existen políticas institucionales que ofrezcan respuestas a las necesidades de los pueblos originarios ni a la aplicación de las disposiciones contenidas en el Convenio 169 de la OIT".

Esta situación se hace más compleja cuando las personas indígenas privadas de libertad son autoridades tradicionales de los pueblos indígenas, como ha sucedido en el contexto del "conflicto intercultural" 6 entre el Estado de Chile y el pueblo mapuche, en situaciones en que autoridades tradicionales y agentes culturales se encuentran encarceladas, como ocurrió en el citado caso Norin Catriman y otros (Dirigentes, miembros y activista del pueblo indígena mapuche) vs. Chile, conocido y fallado por la Corte Interamericana de Derechos Humanos el año $2014^{7}$. Es en este contexto, que en el presente trabajo se aborda una de las dimensiones más relevantes en la protección de los derechos de las personas privadas de libertad indígenas como es la libertad de culto, asociada a las prácticas culturales, que como veremos constituye

\footnotetext{
1 "Dentro de esta categoría se encuentran los pueblos indígenas, respecto de los cuales la Corte ha reconocido que tienen características propias que conforman su identidad cultural, tales como su derecho consuetudinario, sus características económicas, sociales, sus valores, usos y costumbres", Corte Interamericana de Derechos Humanos (CIDH), "Caso Norín Catrimán y otros", 29 de mayo del 2014, párr. 205.

${ }^{2} \mathrm{CADH}$, Artículo 1.1: "Los Estados Partes en esta Convención se comprometen a respetar los derechos y libertades reconocidos en ella y a garantizar su libre y pleno ejercicio a toda persona que esté sujeta a su jurisdicción, sin discriminación alguna por motivos de raza, color, sexo, idioma, religión, opiniones políticas o de cualquier otra índole, origen nacional o social, posición económica, nacimiento o cualquier otra condición social".

${ }^{3}$ CIDH, "Caso Norín Catrimán y otros", 29 de mayo de 2014.

${ }^{4}$ NACIONES UNIDAS (1997), passim.

${ }^{5} \mathrm{INDH}(2018)$, p. 137.

${ }^{6}$ INDH (2015), passim.

${ }^{7}$ CIDH, "Caso Norín Catrimán y otros", 29 de mayo de 2014.
} 
uno de los pilares fundamentales en el respeto de los derechos fundamentales de las personas privadas de libertad.

\section{Regulación penitenciaria y derechos fundamentales}

\subsection{Las personas privadas de libertad como sujetos de derecho}

En el ordenamiento jurídico chileno no existe una ley de ejecución penitenciaria, ni juzgados de ejecución de las penas que regule la relación entre las personas privadas de libertad y el Estado.

El mismo hecho que este sea un reglamento y no una ley se infringe diversos principios orgánicos constitucionales, resguardados en el artículo $64^{8}$ de la Constitución Política. En este sentido, cualquier normativa que aborde la regulación de las condiciones y los derechos de las personas privadas de libertad deben establecerse por ley. Así lo han constatado Carnevali y Maldonado, al afirmar que "nos encontramos con que nuestro Reglamento Penitenciario no cumple con el aspecto formal establecido en la Constitución, toda vez que esta norma tiene un rango inferior a la ley". ${ }^{9}$ En consecuencia, la denominada "actividad penitenciaria" 10 se encuentra regulada a partir del ejercicio de la potestad reglamentaria del poder ejecutivo, ${ }^{11}$ lo que ha generado una serie de debilidades, fundadas principalmente en la falta de reconocimiento de los derechos y garantías de los internos/as y del personal a cargo de ello/as, que consecuencialmente evidencia la necesidad de reconocer a las personas privadas de libertad como sujetos de derecho, siendo necesaria la regulación normativa de la relación entre la persona privada de libertad y el Estado. ${ }^{12}$

Sin perjuicio de lo anterior, el propio artículo $4^{\circ}$ del reglamento contiene una norma de reenvío, estableciendo que "[l]a actividad penitenciaria se desarrollará con las garantías y dentro de los límites establecidos por la Constitución Política de la República, los tratados internacionales ratificados por Chile y vigentes, las leyes y sus reglamentos y las sentencias judiciales". De este artículo se infieren dos ideas, primero que existen garantías fundamentales de las que son agentes los y las privados/as de libertad contempladas en los estándares internacionales, y segundo, que el respeto por estas garantías constituye un límite para el actuar de los agentes del Estado en la tutela de las personas privadas de libertad, cuya infracción genera responsabilidad administrativa y penal a quienes infringen estos límites.

\footnotetext{
${ }^{8}$ CPR. Artículo 64.- El Presidente de la República podrá solicitar autorización al Congreso Nacional para dictar disposiciones con fuerza de ley durante un plazo no superior a un año sobre materias que correspondan al dominio de la ley. Esta autorización no podrá extenderse a la nacionalidad, la ciudadanía, las elecciones ni al plebiscito, como tampoco a materias comprendidas en las garantías constitucionales o que deban ser objeto de leyes orgánicas constitucionales o de quórum calificado. (...)"

${ }^{9}$ CARNEVALI y MALDONADO, (2013), 384-418.

${ }^{10}$ Decreto Supremo $\mathrm{N}^{\circ}$ 518, del año 1998, del Ministerio de Justicia, Art. $1^{\circ}$.

${ }^{11}$ CARNEVALI y MALDONADO (2013), passim.

${ }^{12}$ CENTRO DE POLÍTICAS PÚBLICAS UC (2017) p. 9.
} 


\section{Polít. Crim. Vol. 15, No 29 (Julio 2020), Art. 9, pp. 259-289 \\ [http://politcrim.com/wp-content/uploads/2020/07/Vol15N29A9.pdf]}

\subsection{Estándares internacionales en torno a las personas privadas de libertad}

Ya constatadas las falencias constitucionales en la reglamentación del sistema penitenciario, es relevante indagar acerca de la incorporación de estándares del derecho internacional de los derechos humanos en la materia. En este sentido, los estándares internacionales han sido definidos por Gonzalo Aguilar como:

"el conjunto de instrumentos internacionales de derechos humanos, negociados o aceptados, ya sean vinculantes o no. En consecuencia, los estándares incluyen documentos vinculantes que codifican o crean obligaciones o deberes jurídicos, lo que se conoce comúnmente como hard law, así como los documentos no vinculantes que formulan recomendaciones como normas de conducta y políticas públicas que debieran adoptar los Estados, conocidos como soft law". ${ }^{13}$

Bajo esta perspectiva, los estándares constituyen límites de acuerdo con los cuales debe estructurarse la regulación de todo el proceso de privación de libertad, en atención a la situación de "sujeción especial' ${ }^{14}$ que sitúa a la persona privada de libertad en una condición de vulnerabilidad frente al Estado, el cual debe asumir una posición de garante tal como se ha fijado en la jurisprudencia de la Corte Interamericana de Derechos Humanos.

El derecho internacional de los Derechos Humanos exige a los Estados el deber de tratar humanamente, respetando su dignidad y derechos fundamentales, ${ }^{15}$ a quienes se encuentran a su disposición. Desde esta perspectiva, la sujeción de los/as sujetos a un régimen penitenciario dirigido por el Estado, hace que éste adquiera las obligaciones de respetar y ser garante de sus derechos fundamentales, cuyas restricciones deben ser limitadas a lo proporcional y necesario, de acuerdo a lo que establece el principio de legalidad de la Constitución y la supremacía constitucional, ${ }^{16}$ que se complementan con el principio de servicialidad $^{17}$ a la persona humana y su finalidad, que obliga al Estado a promover la realización espiritual y material de todos y todas.

La situación de vulnerabilidad de las personas privadas de libertad ha generado una especial atención por parte de del derecho internacional de los Derechos Humanos, que valora especialmente la complejidad inherente a la privación de libertad, en que el Estado asume una posición de garante, ${ }^{18}$ superando la anterior doctrina de las 'Relaciones de Sujeción

\footnotetext{
${ }^{13}$ AGUILAR (2015), pp. 23-63.

${ }^{14}$ CASTRO et al. (2010), p.30.

${ }^{15}$ AGUILÓ (2013), p.24.

${ }^{16} \mathrm{CPR}$. Artículo 60.- "Los órganos del Estado deben someter su acción a la Constitución y a las normas dictadas conforme a ella, y garantizar el orden institucional de la República. Los preceptos de esta Constitución obligan tanto a los titulares o integrantes de dichos órganos como a toda persona, institución o grupo. La infracción de esta norma generará las responsabilidades y sanciones que determine la ley”.

${ }^{17} \mathrm{CPR}$. Artículo $1^{\circ}$ inc. $4^{\circ}$ “(...) El Estado está al servicio de la persona humana y su finalidad es promover el bien común, para lo cual debe contribuir a crear las condiciones sociales que permitan a todos y a cada uno de los integrantes de la comunidad nacional su mayor realización espiritual y material posible, con pleno respeto a los derechos y garantías que esta Constitución establece.)

${ }^{18}$ CASTRO et al.(2010), p.23
} 
Especial ${ }^{19}$ utilizada para fundamentar restricciones a los derechos fundamentales de los reclusos.

Respecto de los derechos de las personas privadas de libertad, la Declaración Americana de los Derechos y Deberes del Hombre ${ }^{20}$ establece en su artículo XXV que "[...] Todo individuo que haya sido privado de libertad [...] Tiene derecho también a un tratamiento humano durante la privación de libertad". Así también el Pacto Internacional de Derechos Civiles y Políticos en su artículo 10.1 dispone que "1. Toda persona privada de libertad será tratada humanamente y con el respeto debido a la dignidad inherente al ser humano". Estos principios se unen al artículo $5^{\circ}$ inciso $2^{\circ}$ de la Constitución, ${ }^{21}$ asumiendo la obligación de respetar los tratados internacionales de Derechos Humanos, que como resultado obliga al Estado y a sus agentes a respetar y promover los derechos fundamentales de las personas privadas de libertad, y a su vez, de respetar los derechos de los pueblos indígenas y de sus integrantes, conforme a su dignidad inherente. En este mismo sentido, el artículo $4^{\circ}$ del reglamento penitenciario, incluye una norma de reenvío que incorpora los tratados internacionales de Derechos Humanos: "La actividad penitenciaria se desarrollará con las garantías y dentro de los límites establecidos por la Constitución Política de la República, los tratados internacionales ratificados por Chile y vigentes, las leyes y sus reglamentos y las sentencias judiciales. Los funcionarios que quebranten estos límites incurrirán en responsabilidad, de acuerdo con la legislación vigente".

Para Carnevali y Maldonado, el sistema penitenciario fue evolucionando hasta transformarse en un deber del Estado; en el que los fines preventivo especiales positivos "pasan a operar en términos limitativos, tomando la forma de una restricción del castigo. Pero también, se transforma la obligatoriedad de sus contenidos en una verdadera oferta de participación obligatoria para el Estado - que apela, por sus méritos de forma directa o, finalmente, a través de incentivos, a la asunción de parte del condenado de la conveniencia en su utilización, de cara a la obtención de mejores posibilidades de reinserción y, por ende, de recuperación de la libertad". ${ }^{2}$

Así también, la posición de garante del Estado respecto de las personas privadas de libertad se ha ido desarrollando en la jurisprudencia interamericana. En el caso Miguel Castro vs. Perú ${ }^{23}$ la Corte establece que "[e]l Estado es responsable, en su condición de garante de los derechos consagrados en la Convención, de la observancia del derecho a la integridad personal de todo individuo que se halla bajo su custodia". Luego, en el caso Montero Aranguren y otros (Retén de Catia) Vs. Venezuela ${ }^{24}$ reafirmando que "el Estado se encuentra en una posición especial de garante frente a las personas privadas de libertad, toda vez que

\footnotetext{
${ }^{19}$ RIVERA (2006), p.48

${ }^{20}$ OEA “Declaración Americana sobre Derechos y Deberes del Hombre” T. I Vol. 4, en: www.oas.org/es/cidh/mandato/Basicos/declaracion.asp

${ }^{21}$ CPR. Artículo $5^{\circ}$ inc. $2^{\circ}$ "El ejercicio de la soberanía reconoce como limitación el respeto a los derechos esenciales que emanan de la naturaleza humana. Es deber de los órganos del Estado respetar y promover tales derechos, garantizados por esta Constitución, así como por los tratados internacionales ratificados por Chile y que se encuentren vigentes."

${ }^{22}$ CARNEVALI y MALDONADO (2013), passim.

${ }^{23}$ CIDH, Caso del Penal Miguel Castro Castro Vs. Perú Sentencia, 25 de noviembre de 2006.

${ }^{24} \mathrm{CIDH}$, Caso Montero Aranguren y otros (Retén de Catia) Vs. Venezuela, 5 de julio de 2006.
} 
las autoridades penitenciarias ejercen un fuerte control o dominio sobre las personas que se encuentran sujetas a su custodia”.

\section{Libertad de culto y conciencia como derecho fundamental}

\subsection{Libertad de religión en el derecho internacional}

El derecho a la libertad de religión o de creencias está presente en todas las declaraciones de Derechos Humanos, aparece consagrada en el artículo $18^{25}$ de la Declaración Universal de Derechos Humanos, en el artículo 18 del Pacto Internacional de Derechos Civiles y Políticos, ${ }^{26}$ y en la Declaración sobre la eliminación de todas las formas de intolerancia y discriminación fundadas en la religión o las convicciones, ${ }^{27}$ entre otros.

Por su parte, la Convención Americana de Derechos Humanos protege la "libertad de conciencia y religión" cuando en su artículo 12 refiere que, "el Estado debe tomar las medidas necesarias y proporcionales para que las personas que profesan públicamente sus creencias conduzcan sus ritos y lleven a cabo su proselitismo dentro de los límites que razonablemente puedan imponerse en una sociedad democrática". Esta libertad se también se protege en el artículo $9^{\circ}$ del Convenio Europeo de Derechos Humanos, que protege la "libertad de conciencia, pensamiento y religión", y libertades que son concebidas en ambos sistemas como elementos inherentes a las sociedades democráticas, constituyendo un objeto transversal de protección en los ordenamientos jurídicos contemporáneos.

No existe jurisprudencia de la Corte Interamericana en que se sancione la violación de la libertad religiosa, ${ }^{28}$ sólo se encuentran dos referencias indirectas a la protección de la libertad religiosa, ${ }^{29}$ señalando que el ejercicio de este derecho no puede ser suspendido ni aún en supuestos de estados de excepción ${ }^{30}$. A diferencia del Tribunal Europeo de Derechos Humanos (en adelante TEDH), que en varios casos ha debido definir los alcances del derecho a la libertad de religión definiendo para estos efectos a la libertad de culto como un "valor fundamental para la identidad de los creyentes y su concepción de la vida, pero también para

\footnotetext{
${ }^{25}$ DUDH, Art. 18: “Toda persona tiene derecho a la libertad de pensamiento, de conciencia y de religión; este derecho incluye la libertad de cambiar de religión o de creencia, así como la libertad de manifestar su religión o su creencia, individual y colectivamente, tanto en público como en privado, en la enseñanza, la práctica, el culto y la observancia"

26 "Toda persona tiene derecho a la libertad de pensamiento, de conciencia y de religión. Este derecho incluye la libertad de tener o de adoptar la religión o las creencias de su elección, así como la libertad de manifestar su religión o sus creencias, individual o colectivamente, tanto en público como en privado, mediante el culto, la celebración de los ritos, las prácticas y la enseñanza".

${ }^{27}$ Declaración sobre la eliminación de todas las formas de intolerancia y discriminación fundadas en la religión o las convicciones, Proclamada por la Asamblea General de las Naciones Unidas el 25 de noviembre de 1981 [resolución 36/55].

${ }^{28}$ Por ejemplo en el caso "La Última Tentación de Cristo" (Olmedo Bustos y otros) Vs. Chile, la Corte determinó que no existía infracción al derecho a la libertad religiosa.

${ }^{29}$ CERVANTES (2009), pp. 271-309.

${ }^{30}$ CIDH, Opinión Consulta OC-8/87, del 30 de enero de 1987 y Opinión Consultiva OC-9/87, del 6 de octubre de 1987.
} 
los ateos, agnósticos, escépticos e indolentes". ${ }^{31}$ Para la jurisprudencia del TEDH, la protección de la libertad de culto comprende la protección del derecho a practicar o no una religión, a mudarla, manifestarla individual y colectivamente, en público y en privado, concretándose en el ejercicio del culto, de la enseñanza, y en la práctica y la observancia, como veremos a continuación.

\subsection{Problemas interpretativos de la libertad de religión}

Partiendo del análisis de la Primera Enmienda de la Constitución estadounidense, ${ }^{32}$ Ronald Dworkin considera que la religión es un 'concepto interpretativo', ${ }^{33}$ ya que quienes utilizan este término, no están de acuerdo en su significado, sino que toman una postura respecto a lo que debiese significar. En el debate constitucional respecto al contenido del derecho 'libre ejercicio de la religión' la Corte Suprema estadounidense - analizando un caso relacionado con la objeción de conciencia de una persona atea que se oponía a realizar el servicio militar-, señala que el ser ateo sí califica como religión, ${ }^{34}$ incorporando incluso el 'humanismo secular' como una religión aunque no reconozca un dios en sus creencias ${ }^{35}$. Plantea Dworkin que las personas tienen derecho a ejercer sus convicciones más profundas, sin importar si creen en dios o no, y el gobierno no puede intervenir en ello, proponiendo un derecho general 'independencia ética' ${ }^{36}$ que proteja el núcleo histórico de la libertad religiosa, condenando cualquier discriminación.

Por lo tanto, la libertad religiosa comprende un ámbito muy amplio, incluyendo toda convicción personal, política, filosófica, moral y religiosa, extendiéndose a ideas y convicciones filosóficas de todo tipo. Sin perjuicio de ello, no existe una definición del contenido prima facie $^{37}$ del derecho a la libertad religiosa, que permita indicar un contenido definitivo de este derecho, aun cuando la doctrina ha distinguido diversos ámbitos en los que incorporan en su contenido.

El primer ámbito corresponde a la libertad de conciencia, como la facultad de todas las personas de tener una creencia religiosa. En este sentido, la protección de la libertad de conciencia y de la libertad de religión y culto, se ha concebido dentro del esquema de derechos civiles de primera generación, o bien se han concebido como 'libertades negativas ${ }^{38}$ que se satisfacen sí y solo sí el Estado es estrictamente laico, por lo que se configuran como derechos fundamentales caracterizados por ser derechos de libertad y de

\footnotetext{
${ }^{31}$ TEDH, asunto S.A.S. c. Francia [GC], núm. 43835/2011, ECHR 2014, sobre la prohibición del velo integral en lugares públicos, (§§ 124 y 125)

32 "El Congreso no podrá hacer ninguna ley con respecto al establecimiento de la religión, ni prohibiendo la libre práctica de la misma; ni limitando la libertad de expresión, ni de prensa; ni el derecho a la asamblea pacífica de las personas, ni de solicitar al gobierno una compensación de agravios".

${ }^{33}$ DWORKIN (2014), p.21.

${ }^{34}$ Caso United States vs. Seeger, 380 U.S. 163 (1965)

${ }^{35}$ Caso Torcaso vs. Watkins, 367 U.S. 488 (1961)

${ }^{36}$ DWORKIN (2013), p. 83

${ }^{37}$ LOPERA (2006), p. 137

${ }^{38}$ ATIENZA (2013), p. 74
} 


\section{Polít. Crim. Vol. 15, № 29 (Julio 2020), Art. 9, pp. 259-289 [http://politcrim.com/wp-content/uploads/2020/07/Vol15N29A9.pdf]}

abstención — por parte del Estado- de intervenir en instancias privadas de la fe, en conformidad con el principio de la neutralidad religiosa del Estado. ${ }^{39}$

Existe entonces, dentro de las más íntimas convicciones de la persona, una interpretación teísta/no teísta o atea sobre la espiritualidad, ámbito de convicción. Esta primera dimensión de la libertad de conciencia corresponde entonces a un 'fuero interno de la persona que tiene un carácter inviolable', ${ }^{40}$ que el Estado debe abstenerse de perturbar. En este sentido Nogueira plantea que; “[e]l Estado está imposibilitado de penetrar en este ámbito, debiendo respetar el proceso intelectual y la búsqueda de la verdad que desarrolle autónomamente la persona, como asimismo, su comportamiento externo conforme a su conciencia". ${ }^{41}$

Un segundo plano corresponde a la manifestación de las creencias personales sin interferencia de terceros o del Estado; en público o en privado, de forma individual o colectiva. El artículo $6^{\circ}$ de la Declaración sobre la eliminación de todas las formas de intolerancia y discriminación fundadas en la religión o las convicciones enumera ciertos casos expresando que todas las personas tienen la libertad de practicar el culto o de celebrar reuniones en relación con la religión o las convicciones, y de fundar y mantener lugares para esos fines; la libertad de confeccionar, adquirir y utilizar en cantidad suficiente los artículos y materiales necesarios para los ritos o costumbres de una religión o convicción; escribir, publicar y difundir publicaciones pertinentes en esas esferas; enseñar la religión o las convicciones en lugares aptos para esos fines; solicitar y recibir contribuciones voluntarias financieras y de otro tipo de particulares e instituciones; capacitar, nombrar, elegir y designar por sucesión los dirigentes que correspondan según las necesidades y normas de cualquier religión o convicción; observar días de descanso y de celebrar festividades y ceremonias de conformidad con los preceptos de una religión o convicción; y así también la libertad de establecer y mantener comunicaciones con individuos y comunidades acerca de cuestiones de religión o convicciones en el ámbito nacional e internacional.

En un tercer plano, podemos encontrar la libertad religiosa, en lo referente a la capacidad de conservar una religión o cambiar libremente de ella, ${ }^{42}$ es decir el derecho a cambiar de religión, sin coacción o interferencia alguna.

En estas tres dimensiones del derecho a la libertad de culto, el ámbito protegido de este derecho fundamental debe ser el máximo posible. Es necesario distinguir entre las dimensiones interna/externa de la libertad religiosa. El derecho a tener una religión o creencia determinada no puede ser limitado en ningún caso, ${ }^{43}$ a diferencia del derecho a manifestar dicha religión o creencia, ámbito en que sí existen limitaciones en atención a otros intereses que el Estado debe salvaguardar.

Las limitaciones a las libertades religiosas hoy son un debate relevante en el contexto de la globalización y de la multiculturalidad. El contenido este derecho —n su dimensión

\footnotetext{
${ }^{39}$ PAUL (2016), pp.269-287.

${ }^{40}$ NOGUEIRA (2008), p. 11

${ }^{41}$ NOGUEIRA (2006), pp.13-41.

${ }^{42}$ ESCOBAR (2017), pp.125-138.

${ }^{43}$ HUICI (2015), p. 65.
} 
externa- no es absoluto. Conforme a la 'teoría externa', “el ámbito protegido amplio o contenido extenso del derecho fundamental está sujeto a restricciones, las que deberán provenir de otros derechos o bienes de equivalente rango jerárquico" ${ }^{4}$, es necesario comprender la libertad de culto como un derecho limitable, ya que se encuentra en permanente contacto con el ejercicio de otros derechos, o con la protección de otros bienes jurídicos.

Hoy, el carácter universal de las creencias y de las religiones coincide en su potencial expansión con la superación de barreras y límites de la globalización, mientras que el propio desarraigo humano provocado por la globalización genera también la búsqueda de identidad y de símbolos de pertenencia ${ }^{45}$, que profundizan las necesidades y/o manifestaciones espirituales ligadas a una identidad cultural.

Lo interesante jurídicamente entonces, es delimitar el ejercicio de estas expresiones religiosas, por ejemplo, en Francia se introdujo la prohibición de usar velos musulmanes y otros símbolos religiosos "visibles" en las escuelas estatales. Además, el 2010 se prohibió, en el espacio público, vestir prendas diseñadas para ocultar el rostro de las mujeres como el burka o el nicab, por considerar que esta conducta, - en particular cuando se utiliza el denominado velo integral—, se contraponía con la seguridad pública y los valores de una sociedad democrática. ${ }^{46}$ Asimismo, se prohibió el uso de turbantes en las fotografías identificativas de documentos identificatorios, ${ }^{47}$ medida que fue impugnada por hombres pertenecientes a la religión Sij, pero que fue finalmente respaldada por el Tribunal Europeo de Derechos Humanos (TEDH). En otros casos, el TEDH estableció que la protección de la salud pública debe prevalecer sobre la libertad religiosa, en caso planteado por una representante de la comunidad Daimista, que solicitaban la admisión del consumo de ayahuasca en sus ritos; ${ }^{48}$ o que la libertad religiosa debe ceder el ejercicio individual de la libertad religiosa cuando ocasione problemas de orden público. ${ }^{49}$

Como vemos, las problemáticas asociadas a las libertades religiosas son múltiples, y en nuestro objeto de estudio se atraviesan, con la pertenencia a grupos vulnerables, estar privado/a de libertad y pertenecer a un pueblo indígena.

\section{La libertad de culto en el ámbito penitenciario}

La libertad religiosa de las personas privadas de libertad se encuentra protegida en varios niveles. En el ámbito del derecho internacional de los Derechos Humanos, el respeto por las libertades religiosas se encuentra regulado en las Reglas mínimas para el tratamiento de los reclusos, ${ }^{50}$ en los numerales 40, 41 y 42, que señalan que — en la medida de lo posible —, se

${ }^{44}$ UGARTE (2011), pp. 361-373.

${ }^{45}$ PALOMINO (2009), pp. 509-548.

${ }^{46}$ TEDH, S. A. S. c. Francia, sentencia del 1 de julio de 2014.

${ }^{47}$ BRIONES (2009), pp. $17-82$, p. 21.

${ }^{48}$ Decisión de Inadmisión Alida Maria Fränklin-Beentjes y Ceflu-Luz da Floresta c. Holanda, de 6 de mayo de 2014.

${ }^{49}$ Decisión de Inadmisibilidad Rosemary Fairfield y otros c. el Reino Unido, de 8 de marzo de 2000.

${ }^{50}$ Reglas mínimas para el tratamiento de los reclusos Adoptadas por el Primer Congreso de las Naciones Unidas sobre Prevención del Delito y Tratamiento del Delincuente, celebrado en Ginebra en 1955, y aprobadas por el 


\section{Polít. Crim. Vol. 15, No 29 (Julio 2020), Art. 9, pp. 259-289 [http://politcrim.com/wp-content/uploads/2020/07/Vol15N29A9.pdf]}

autorizará a todo recluso a cumplir los preceptos de su religión, permitiendo además el nombramiento de un representante del culto de las personas internas, quien dependiendo del número de reclusos lo justifique, y de las circunstancias lo permitan, deberá prestar este servicio religioso con carácter continuo.

En el ámbito interno, la Constitución Política de Chile en su artículo $19 \mathrm{~N}$ 6, asegura a las personas: "La libertad de conciencia, la manifestación de todas las creencias y el ejercicio libre de todos los cultos que no se opongan a la moral, a las buenas costumbres o al orden público [...]". Por su parte, el artículo $6^{\circ}$ de la 'Ley de Culto' reconoce como derechos los diversos ámbitos de la libertad religiosa y — en una vereda opuesta a la normativa francesareconoce el derecho a:

"[...] practicar en público o en privado, individual o colectivamente, actos de oración o de culto; conmemorar sus festividades; celebrar sus ritos; observar su día de descanso semanal; recibir a su muerte una sepultura digna, sin discriminación por razones religiosas; no ser obligada a practicar actos de culto o a recibir asistencia religiosa contraria a sus convicciones personales y no ser perturbada en el ejercicio de estos derechos". ${ }^{1}$

Específicamente sobre las personas privadas de libertad, la ley de culto protege el derecho a recibir asistencia religiosa, de su propia confesión donde quiera que se encuentre, dejando su regulación en cárceles y lugares de detención, en decretos y reglamentos.

A nivel reglamentario, el inciso $2^{\circ}$ del artículo $6^{\circ}$ del reglamento penitenciario enumera una serie de garantías para las personas privadas de libertad, señalando que: "Se garantiza la libertad ideológica y religiosa de los internos, (...)”. Asimismo, el inciso $2^{\circ}$ del artículo $6^{\circ}$ del Reglamento establece que: "se garantiza la libertad ideológica y religiosa de los internos, su derecho al honor, a ser designados por su propio nombre, a la intimidad personal, a la información, a la educación y el acceso a la cultura, procurando el desarrollo integral de su personalidad, y a elevar peticiones a las autoridades, en las condiciones legalmente establecidas". Por su parte, el artículo $2^{\circ}$ el Reglamento establece que: "Será principio rector de dicha actividad - la actividad penitenciaria - el antecedente que el interno se encuentra en una relación de derecho público con el Estado, de manera que fuera de los derechos perdidos o limitados por su detención, prisión preventiva o condena, su condición jurídica es idéntica a la de los ciudadanos libres".

En concordancia con estas normas, el lugar de privación de libertad debiera mantener espacios para que los/as internos/as pertenecientes a alguna religión o culto puedan ejercer sus derechos espirituales. Por ejemplo, existe un programa llamado "Ministerio Carcelario"52 que tiene vigencia desde el año 2015, cuyo objetivo principal es predicar el evangelio en los recintos penitenciarios de Chile, realizar labores de reinserción social de los reos y brindar apoyo a las familias en la libertad. En el caso de quienes profesan la religión católica, existe

Consejo Económico y Social en sus resoluciones 663C (XXIV) de 31 de julio de 1957 y 2076 (LXII) de 13 de mayo de 1977.

${ }^{51}$ Ley 19.638, Art. $6^{\circ}$

${ }^{52}$ CASTAÑEDA (2011), passim. 
una Capellanía Nacional Católica ${ }^{53}$ que tiene como misión el trabajo pastoral dentro de las unidades penales del país. No existe ningún programa o reglamentación sobre la religiosidad de las personas indígenas privadas de libertad.

\section{Derechos Humanos de los/as privadas de libertad y derechos de los pueblos indígenas}

Si bien los 'Derechos Humanos' han sido criticados como una construcción conceptual occidental, que tiene un trasfondo eurocéntrico y colonial, ${ }^{54}$ en la práctica, el contenido de estas normas permite reafirmar los derechos culturales de los pueblos, quienes, en un contexto de disputa interétnica y territorial, han utilizado Derechos Humanos para encuadrar sus propias demandas e instalar un sentido contra hegemónico de los Derechos Humanos, como ha sido el caso de las reivindicaciones de las personas privadas de libertad pertenecientes al pueblo mapuche. En este sentido Antona constata que:

"Este fenómeno pone de relieve un cambio de estrategia y actitud de los pueblos indígenas americanos en relación con los derechos humanos que consiste en dejar atrás el clásico rechazo difundido por el indianismo, aludiendo al etnocentrismo y al colonialismo, para centrarse en la tarea de pugnar por el sentido que se otorga a los derechos humanos para contrarrestar la hegemonía que ejerce Occidente, contraponiendo para ello sus saberes ancestrales al servicio de esta causa". ${ }^{55}$

El derecho internacional de los Derechos Humanos fue desarrollando durante el siglo XX, un sistema de protección de los derechos de los pueblos indígenas, que en la actualidad se encuentran principalmente en el Convenio 169 de la Organización Internacional del Trabajo y en la Declaración de las Naciones Unidas sobre los Derechos de los Pueblos Indígenas del año 2007. Respecto a la libertad de culto de las personas indígenas, el Convenio 169 en su artículo 5 dispone que: "Al aplicar las disposiciones del presente Convenio: a) deberán reconocerse y protegerse los valores y prácticas sociales, culturales, religiosos y espirituales propios de dichos pueblos y deberá tomarse debidamente en consideración la índole de los problemas que se les plantean tanto colectiva como individualmente; b) deberá respetarse la integridad de los valores, prácticas e instituciones de esos pueblos". Así también, el artículo $8^{\circ}$ del Convenio establece que pueblos deberán tener el derecho de conservar sus costumbres e instituciones y que: "Al aplicar la legislación nacional a los pueblos interesados deberán tomarse debidamente en consideración sus costumbres o su derecho consuetudinario [...]". En relación a las personas indígenas privadas de libertad, destaca el artículo $10^{\circ}$ del Convenio 169 de la OIT, de acuerdo al cual: "1. Cuando se impongan sanciones penales previstas por la legislación general a miembros de dichos pueblos deberán tenerse en cuenta sus características económicas, sociales y culturales. 2. Deberá darse la preferencia a tipos de sanción distintos del encarcelamiento".

Por su parte, la Declaración de las Naciones Unidas sobre los Derechos de los Pueblos Indígenas (DNUPI) aprobada en el año 2007 por la Asamblea General las Naciones Unidas

\footnotetext{
${ }^{53} \mathrm{http} / / /$ www.caritaschile.org/carcel.php

${ }^{54}$ DE SOUZA SANTOS (2014), p. 25.

${ }^{55}$ ANTONA (2014), pp. 429-452, p.433.
} 


\section{Polít. Crim. Vol. 15, № 29 (Julio 2020), Art. 9, pp. 259-289 \\ [http://politcrim.com/wp-content/uploads/2020/07/Vol15N29A9.pdf]}

plantea que los y las indígenas tienen derecho, como pueblos o como individuos, al disfrute pleno de todos los Derechos Humanos y las libertades fundamentales reconocidos en la Carta de las Naciones Unidas, la Declaración Universal de Derechos Humanos y las normas internacionales de Derechos Humanos ${ }^{56}$ y tienen derecho a no ser objeto de ningún tipo de discriminación en el ejercicio de sus derechos, en particular la fundada en su origen o identidad indígenas. ${ }^{57}$ Específicamente en relación a la libertad de culto, el artículo 12.1 de la Declaración dispone que: "Los pueblos indígenas tienen derecho a manifestar, practicar, desarrollar y enseñar sus tradiciones, costumbres y ceremonias espirituales y religiosas; a mantener y proteger sus lugares religiosos y culturales y a acceder a ellos privadamente; a utilizar y controlar sus objetos de culto, y a obtener la repatriación de sus restos humanos $[\ldots] "$.

Finalmente, la Convención Internacional sobre la Eliminación de todas las Formas de Discriminación Racial, en su artículo $5^{\circ}$ establece que: “[...] los Estados partes se comprometen a prohibir y eliminar la discriminación racial en todas sus formas y a garantizar el derecho de toda persona... el derecho a la libertad de pensamiento, de conciencia y de religión... el derecho a la libertad de reunión y de asociación pacíficas".

De acuerdo con estas disposiciones, existe un deber de los Estados de respetar y garantizar el ejercicio de la espiritualidad de los pueblos indígenas sin discriminación alguna, alcance que evidentemente incorpora a quienes se encuentran en esta relación de sujeción con el Estado, en razón a la privación de libertad. Uno de los aspectos relevantes en el ejercicio concreto de estas prerrogativas, dice relación con los derechos de los y las indígenas privados de libertad y con la posibilidad que tienen al interior de las unidades penales para el ejercicio de sus tradiciones, costumbres y ceremonias. ${ }^{58}$

Ya definido el marco normativo y los alcances interpretativos de la protección de la libertad de culto de las personas indígenas privadas de libertad, pasaremos a una segunda parte de este trabajo que analiza específicamente la relación entre comuneros mapuche privados de libertad y el Estado de Chile.

\footnotetext{
${ }^{56}$ DNUPI, Art. $1^{\circ}$

${ }^{57}$ DNUPI, Art. $2^{\circ}$

${ }^{58}$ En este sentido el 1 Convenio 169 establece en su artículo $8^{\circ}$ que "1. Al aplicar la legislación nacional a los pueblos interesados deberán tomarse debidamente en consideración sus costumbres o su derecho consuetudinario. 2. Dichos pueblos deberán tener el derecho de conservar sus costumbres e instituciones propias, siempre que éstas no sean incompatibles con los derechos fundamentales definidos por el sistema jurídico nacional ni con los derechos humanos internacionalmente reconocidos. Siempre que sea necesario deberán establecerse procedimientos para solucionar los conflictos que puedan surgir en la aplicación de este principio. La aplicación de los párrafos 1 y 2 de este artículo no deberá impedir a los miembros de dichos pueblos ejercer los derechos reconocidos a todos los ciudadanos del país y asumir las obligaciones correspondientes"
} 


\section{El sistema penitenciario como dispositivo cultural}

\subsection{Azotes, trabajo y disciplina: introducción a la historia del sistema penitenciario}

A lo largo de la historia, cada sociedad ha sancionado las conductas transgresoras de sus miembros de formas muy diversas, que van desde el castigo corporal, hasta el actual sistema de encarcelamiento. En la actualidad, las penas privativas de libertad son la base del sistema punitivo de las sociedades modernas, y son, en definitiva, el resultado de una evolución racionalizadora y humanitaria del Derecho penitenciario ${ }^{59}$, que poco ha ido incorporando nuevas problemáticas y desafíos jurídicos.

Durante la colonia, el sistema represivo hacia quienes trasgredían las normas, tenía como eje central el castigo físico y el tormento público como un mecanismo de disuasión por la vía del castigo ejemplarizador. Previo a la promulgación del Código Penal, el castigo penal se traducía en ejecuciones públicas, uso de tormento y la humillación de los reos, como un mecanismo de ejercicio de violencia en contra de los cuerpos de quienes eran condenados/as. En aquel entonces, la cárcel era concebida como un lugar de tránsito, en el que se esperaban condenas mayores, como la ejecución pública, la expropiación de bienes o el destierro. ${ }^{60}$ Incluso actos que hoy son considerados ilícitos menores, eran castigados con la pena de azotes.

Ya a comienzos del siglo XIX, la gran cantidad de motines que se produjeron en las cárceles de Chile, plantearon la necesidad de reformar el sistema carcelario existente. Esta transformación significó al igual que en Estados Unidos y Europa ${ }^{61}$ - la introducción de una nueva metodología del trato correccional ${ }^{62}$ - que buscaba principalmente la sujeción de los cuerpos de los reos a alguna actividad laboral. Ya en el siglo XX, se promulgó el Reglamento Constitucional Provisorio de 1812, que en su artículo 21, regulaba constitucionalmente el tratamiento penitenciario, incorporando por primera vez una perspectiva humanitaria acerca de las condiciones carcelarias: "Las prisiones serán lugares cómodos y seguros para la detención de personas, contra quienes existan fundados motivos de recelo, y mientras duren éstos; y de ningún modo servirán para mortificar delincuentes". ${ }^{63}$

Partiendo de la premisa que la cárcel es un dispositivo de control social ${ }^{64}$ que pertenece a la cultura jurídica propia de la modernidad occidental, esta investigación pretende evidenciar el carácter histórico de la cárcel como dispositivo de control social y de resocialización de los condenados/as.

El criminólogo Jonathan Simon al abordar la relación entre poder, autoridad y justicia penal también evidencia que al igual que en la historia europea, hasta la modernidad temprana las

\footnotetext{
${ }^{59}$ PASTOR y TORRES (2017), pp. 124-150.

${ }^{60}$ LEÓN (1998), passim.

${ }^{61}$ MELOSSI y PAVARINI (1980), passim.

${ }^{62}$ FERNÁNDEZ (1998), p. 46

${ }^{63}$ Reglamento Constitucional Provisorio de 1812, Artículo 21.

${ }^{64}$ FOUCAULT (2009), passim.
} 
familias y los clanes eran los responsables de resolver situaciones de conflictos interpersonales, lo cual se fue transformando en el tiempo:

"En términos históricos, el Estado fue garantizando sólo en forma paulatina el poder de sancionar delitos y garantizar el orden cívico, y antes del siglo veinte, el "monopolio" de la violencia legítima, tantas veces invocada en nombre del Estado, no era más que una ficción, aún en los países avanzados". ${ }^{5}$

Este ideal de un nuevo modelo penal va surgiendo, junto a la expansión de un discurso del Estado como entidad regeneradora y moralizante, ${ }^{66}$ que estructura el control del delito a través del encierro y la resocialización. Dentro del nuevo tratamiento penitenciario, se instala el paradigma de la prevención especial positiva, cuyo norte es la reinserción social, que se logra "asegurando a la comunidad frente a los delincuentes, mediante el encierro de éstos; intimidando al autor, mediante la pena, para que no cometa futuros delitos; y preservándole de la reincidencia mediante su corrección". ${ }^{67}$ El tratamiento distingue y clasifica según el tipo de reo: "la inocuización del delincuente habitual de quien no se puede conseguir que desista ni que mejore; la intimidación del mero delincuente ocasional y la corrección del autor corregible". ${ }^{68}$

En Chile, el paradigma penitenciario, se vio reforzado por la necesidad de control social durante los primeros años de la República chilena, consolidado en un modelo de gobierno autoritario, sustentado en las ideas de Diego Portales, para quien la regeneración de los delincuentes se realizaba mediante el trabajo forzado. La introducción del sistema penitenciario tiene una relevancia política en la forma en que el Estado se impone ante la sociedad, ya que en palabras de Simons: "toda autoridad legal se basa, en última instancia, en la amenaza del ejercicio legal de la violencia en el marco de la justicia penal". ${ }^{69}$

Por ello, en 1836, se creó el sistema de 'Presidio Ambulante', consistente en carros de metal que trasladaban a los presidiarios a trabajar en obras públicas. ${ }^{70}$ Este sistema, tenía como elemento central la humillación de los presos, con la finalidad de amedrentar a futuros delincuentes y hacer presente el poder del Estado ante los ciudadanos. Ya en 1843, durante el gobierno de Manuel Bulnes, se dictó la primera ley referida al tema carcelario. El nuevo sistema penal moderno, tuvo como símbolo la construcción de la Penitenciaría de Santiago en 1847, que apuntaba a la concreción de las características que debían tener las cárceles según la ley referida: separar a los reos según sus particularidades; imponerles una jornada de trabajo productivo; y además instruirlos en la fe y las primeras letras, como una instancia de disciplinamiento y corrección moral, al tenor de las teorías penitenciarias modernas. ${ }^{71}$

\footnotetext{
65 SIMON (2007), p. 27.

${ }^{66}$ BELLO et al. (2005).

${ }^{67}$ ROXIN (1999), pp. 81-82.

${ }^{68}$ ROXIN (1999), pp.85-86.

${ }^{69}$ SIMON (2007), p. 28.

${ }^{70}$ LEÓN (2003), passim.

${ }^{71}$ LEON (1998), passim.
} 
En adelante, la cárcel se transformó en un lugar de ejecución de la pena, que era a la vez, un lugar de privación de la libertad y de trasformación técnica de los individuos ${ }^{72}$, quienes a través de la observación constante y del castigo correccional, alcanzan el disciplinamiento, y el control de los cuerpos. ${ }^{73}$

\subsection{Sistema penitenciario y colonialismo interno}

La construcción del sistema jurídico chileno se caracteriza por ser producto de un proceso histórico en que se han desconocido importantes aspectos normativos de la cultura de los pueblos originarios, lo cual se refleja a nuestro juicio, en la falta de reconocimiento constitucional de los pueblos indígenas. Por lo tanto, el ordenamiento jurídico chileno se caracteriza, desde sus orígenes, por ser un modelo monocultural, donde solo muy excepcionalmente se valora el derecho indígena o 'la costumbre', ${ }^{74}$ constituyéndose como un dispositivo de colonialismo interno ${ }^{75}$, en el que se reniega el valor del conocimiento y de la praxis de las culturas originarias.

El colonialismo interno se ha sustentado las estructuras de Estados-Nación del continente, los que asumieron como condición fundamental la imposición de un sistema de clasificación social sustentado sobre la idea de raza, con la que se niega la existencia de los pueblos originarios $\mathrm{y}$, por supuesto, de sus territorios ${ }^{76}$. La epistemología, como teoría del conocimiento que pretende explicar los sucesos históricos y sociológicos de una sociedad, y a su vez, fundamenta las diferentes realidades a través de los conceptos de "verdad"77, y contribuye a la formación del pensamiento de cada sociedad, y al vínculo de ésta con su entorno natural. En este sentido, Boaventura de Souza Santos ${ }^{78}$, planeta que los procesos coloniales han generado como consecuencia un 'epistemicidio' de los saberes indígenas. Este ejercicio de poder, opera a través de la 'colonialidad del saber' ${ }^{79}$ que niega el valor de los conocimientos propios de los pueblos indígenas.

En el ámbito jurídico, el colonialismo interno se manifiesta en la imposición de un sistema monista, en que sólo se considera válido el derecho occidental. El monismo jurídico ${ }^{80}$, es también un "modelo de la asimilación propio de los ordenamientos liberales, que sin poner en cuestión la parcialidad del sujeto del modelo precedente, lo asumieron como un término 'normal' y 'normativo' de la igualdad, idóneo para incluir a los demás, sólo en cuanto homologados con él" ${ }^{\prime \prime}$.

\footnotetext{
${ }^{72}$ FOUCAULT (2009), p. 228

${ }^{73}$ FOUCAULT (2009), p. 228

${ }^{74}$ Ley 19.253 “Artículo 54.- La costumbre hecha valer en juicio entre indígenas pertenecientes a una misma etnia, constituirá derecho, siempre que no sea incompatible con la Constitución Política de la República. En lo penal se la considerará cuando ello pudiere servir como antecedente para la aplicación de una eximente o atenuante de responsabilidad"

${ }^{75}$ GONZÁLEZ (2003), pp. 1-30.

${ }^{76}$ MELIN et al. (2019), p. 17.

${ }^{77}$ CORREA y SALGARRIAGA (2014), passim.

${ }^{78}$ DE SOUSA SANTOS (2009), p 368.

${ }^{79}$ LANDER (1993), passim.

${ }^{80}$ WOLKMER (2006), passim.

${ }^{81}$ FERRAJOLI (1999), p. 76.
} 


\section{Polít. Crim. Vol. 15, № 29 (Julio 2020), Art. 9, pp. 259-289 [http://politcrim.com/wp-content/uploads/2020/07/Vol15N29A9.pdf]}

En consecuencia, la implantación del monismo jurídico ha significado la desvalorización del derecho propio de los pueblos indígenas y la imposición de pautas de comportamientos ajenas a su realidad, relegando los sistemas jurídicos propios a espacios al margen de la oficialidad, cuya ausencia fue llenada de normas y principios del sistema occidental. Como lo explica Ester Sánchez Botero:

"uno de los efectos del Estado monocultural sobre los pueblos indígenas fue la sistemática imposición de los principios y formas de organización en la vida social, del manejo de los recursos públicos como así del control y solución de conflictos, principios y estructura y enfoque de un derecho que necesariamente no coincidía —en parte o en su totalidad - con los sistemas existentes en cada uno de los pueblos". ${ }^{82}$

Por lo tanto, es necesario concluir que la existencia de un sistema jurídico en territorios históricamente habitados por los pueblos indígenas obedece a un proceso histórico de extensión del Estado y de su poder punitivo. Este modelo, no incorpora las concepciones y epistemologías propias de la cultura de los pueblos originarios.

A continuación, analizaremos específicamente el caso del pueblo mapuche, abordando la situación actual de conflicto con el Estado de Chile, y algunos aspectos de su espiritualidad (feyentun) y de su sistema normativo (Az Mapu).

\section{Pueblo Mapuche en Chile}

El censo del año $2017^{83}$ dio cuenta que el $13 \%$ de la población de Chile se declara perteneciente algún pueblo indígena, y que 9,9\% (1.745.147) de ella, menciona pertenecer al pueblo mapuche, posicionándose como el principal pueblo originario con presencia en el país.

El pueblo mapuche se ha caracterizado históricamente por la reivindicación de sus derechos culturales y por la protección de su territorio ancestral a través de la protesta social ${ }^{84}$ Estas movilizaciones se han incrementado el último tiempo debido a la presencia de empresas forestales y a la construcción de proyectos de desarrollo, desprovistos de instancias de diálogo intercultural ${ }^{85}$ lo que ha llevado a la agudización del conflicto 'intercultural ${ }^{86}$ entre este pueblo originario y el Estado chileno, que hoy se posiciona en el centro del debate nacional.

La intensificación de la situación de conflicto que existe entre el pueblo mapuche y el Estado chileno $^{87}$ ha traído como consecuencia el aumento de la violencia política, asociada a las dinámicas de protesta social, que son enfrentadas por el Estado mediante la utilización de la

\footnotetext{
${ }^{82}$ SÁNCHEZ (2003), p. 2.

${ }^{83}$ GOBIERNO DE CHILE, CENSO (2017), passim.

${ }^{84}$ AYLWIN et al. (2013), p. 115 y ss.

${ }^{85}$ CEPAL-ATM (2012), passim.

86 "Lo que genéricamente es conocido como 'conflicto mapuche', para otros es un 'conflicto entre las demandas del pueblo mapuche y el Estado de Chile, derivado de la 'deuda histórica' del Estado. Para otros sectores, es un fenómeno de 'respuesta radical violenta de algunos grupos' o 'terrorismo", en INDH (2014), p. 18.

${ }^{87}$ PINTO (2014), p. 180.
} 
Ley de Seguridad del Estado o Ley Antiterrorista, lo que para parte de la doctrina nacional, como Myrna Villegas constituye una manifestación de la aplicación del Derecho Penal del enemigo, ${ }^{88}$ que dan cuenta de cómo las reivindicaciones del pueblo mapuche han sido abordadas desde el campo del control del delito y la justicia penal.

Sobre este último punto, la Corte Interamericana el año 2014 condenó al Estado de Chile, en el caso "Norín Catriman y otros v/s Chile" 89 constatando que a partir del año 2001 se incrementó significativamente el número de dirigentes y miembros de comunidades mapuche investigados y juzgados por la comisión de delitos ordinarios en relación con actos violentos asociados a la 'protesta social' y a la aplicación de la Ley Antiterrorista. ${ }^{90}$

Uno de los efectos de la efervescencia del este conflicto, ha sido el aumento de comuneros/as mapuche privado/as de libertad en las cárceles de la Araucanía y del Bío Bío, ${ }^{11}$ quienes al interior de estos recintos mantienen demandas asociadas al reconocimiento de sus derechos individuales y colectivos como la libertad de culto o la libertad de expresión, siendo los casos del Machi ${ }^{92}$ Celestino Córdova y de la Machi Francisca Linconao los más relevantes en el debate nacional ${ }^{93}$.

\subsection{Feyentun: espiritualidad mapuche}

Tanto la Ley Indígena ${ }^{94}$ como el Derecho internacional de los Derechos Humanos protegen como derecho de los integrantes de los pueblos indígenas a gozar de la particular relación espiritual con la naturaleza.

En el caso del pueblo mapuche, existe una religión propia en la que la naturaleza es un elemento esencial en la cosmovisión y en la espiritualidad de quienes integran este pueblo. La espiritualidad mapuche se fundamenta en el feyentun, que corresponde a su sistema de creencias, en el universo o Wallmapu en que habita está poblado por energías de la naturaleza que se interrelacionan con las personas en un vínculo horizontal e integrado, en que todos los seres vivos poseen un mismo lugar. Desde esta perspectiva, la relación con la naturaleza es un vínculo espiritual de interacción, que se fundamenta en pedir permiso, es una relación de reconocimiento, de respeto y reciprocidad con el entorno natural. El bienestar va más allá de

\footnotetext{
${ }^{88}$ VILLEGAS (2008), pp. 423-464

${ }^{89} \mathrm{CIDH}$, “Caso Norín Catrimán y otros”, 29 de mayo del 2014 p. 85.

${ }^{90}$ VILLEGAS (2018), passim.

${ }^{91}$ MELI WIXAN MAPU (2018), passim.

${ }^{92}$ Los y las machi corresponden a autoridades espirituales mapuche, que tienen la responsabilidad mantener la salud de su pueblo, intermediar entre los espíritus y el hombre, y resguardar el AzMapu, o derecho propio configurándose como intermediarios entre el mundo espiritual y el material. En MELIN (2015), passim.

${ }^{93}$ LA TERCERA, "Más de 260 carabineros y gendarmes custodiaron a machi Celestino en rewe", en https://www.latercera.com/nacional/noticia/mas-260-carabineros-gendarmes-custodiaron-machi-celestinorewe/261352/\#https://www.latercera.com/nacional/noticia/asi-rewe-altar-mapuche-celestino-cordova-insistiovisitar/259853/\# [visitado el 07 de mayo de 2019]

${ }^{94}$ Ley 19.253, Art. 7: "El Estado reconoce el derecho de los indígenas a mantener y desarrollar sus propias manifestaciones culturales. El Estado tiene el deber de promover las culturas indígenas, las que forman parte del patrimonio de la Nación chilena"
} 


\section{Polít. Crim. Vol. 15, № 29 (Julio 2020), Art. 9, pp. 259-289 [http://politcrim.com/wp-content/uploads/2020/07/Vol15N29A9.pdf]}

la salud física o psicológica individual, sino que también está relacionado con el bienestar de la familia, comunidad y el entorno natural que rodea a una persona ${ }^{95}$.

La relación con la tierra y los demás seres, también se realiza a través de celebraciones espirituales como los Nguillatun ${ }^{96}$, que son ceremonias de gran importancia política y social, como así también ceremonias de carácter espiritual como los Llellipun que corresponden a las rogativas, siendo las ceremonias más relevantes y significativas para la cultura mapuche. Siguiendo el principio del Kvme Mongen (Buen Con-Vivir), la persona mapuche cree en una vida en armonía con todos los seres, con los demás hombres y mujeres, con Dios o Ngechen y las fuerzas espirituales y con la naturaleza en sus infinitas manifestaciones y con uno mismo ${ }^{97}$.

En el sistema mapuche todo lo que ocurre en la naturaleza afecta a las personas; si se rompe el equilibrio con ésta se sufre las consecuencias del desequilibrio, generándose enfermedad tanto física como espiritual. ${ }^{98}$ En este sentido, la salud se concibe como el equilibrio de la persona, el bienestar en los estados económico, social, personal, familiar y territorial. La participación en las ceremonias espirituales es trascendental en la mantención del bienestar de la persona mapuche, y se vincula directamente con su salud, ya que son una forma de conectarse con la espiritualidad.

En especial, las personas mapuche que ocupan roles culturales y espirituales, necesitan permanecer en contacto con el mundo natural, prácticas impedidas por la falta de acceso a espacios naturales y abiertos que les permite conectarse con el mundo espiritual. En consecuencia, las condiciones de encierro generan en las personas mapuche impedidas de ejercer sus derechos espirituales, situaciones de deterioro de la salud, siendo la cárcel una barrera que impide la conexión espiritual con el entorno natural.

\subsection{AzMapu y Derecho occidental}

Antes y paralelamente a la imposición del sistema jurídico nacional, el pueblo mapuche se organizaba en torno al AzMapu ${ }^{99}$ o derecho propio mapuche. Entre los componentes éticonormativos del AzMapu figuran el yamuwün o respeto a las personas, la naturaleza y la palabra, el igkawün o apoyo mutuo y la defensa de la tierra, el kümechegerpuam o llegar a ser una buena persona, entre muchos otros componentes. ${ }^{100}$ Para Sánchez Curihuentro, el Az Mapu define el hacer y no hacer como una manera de respetar y mantener un equilibrio..$^{101}$ Por su parte Antona lo define como un término que "condensa un amplio campo semántico

\footnotetext{
${ }^{95}$ QUIDEL (2005), pp. 153-166.

${ }^{96} \mathrm{El}$ Ngillatun es una de las principales ceremonias socio-religiosa Mapuche. “(...) Es un acto de comunión conjunta con günechen para que el ciclo natural del año tenga un buen equilibrio con la naturaleza y el medio", en CONSEJO NACIONAL DE LA CULTURA Y LAS ARTES (2001), passim.

${ }^{97}$ QUIDEL (2005), passim.

${ }^{98}$ DÍAZ et al. (2004) p. 9-16.

${ }^{99}$ MELIN (2015), passim.

${ }^{100}$ MELIN (2015), passim.

${ }^{101}$ SÁNCHEZ CURIHUENTRO (2001), p. 37.
} 
que alude a la moral ancestral y a la ley suprema, es la gran declaración de principios que se dio el Pueblo Mapuche para relacionarse entre sí y con la naturaleza". ${ }^{102}$

En el caso del pueblo mapuche, la privación de libertad no es parte de su derecho propio o AzMapu, la persona mapuche puede incurrir en faltas a la norma de vida transgrediendo espacios y dimensiones que son necesarias para el equilibrio de la vida, pero las sancionan apuntan más hacia lo que Myrna Villegas considera como 'una justicia restaurativa', ${ }^{103}$ propiciando mecanismos de sanción distintos a la cárcel. Cuando los consejos (gvlam) y los mecanismos preventivos fallan, las formas de solución van desde mecanismos de autocomposición hasta la autotutela, y la intervención de un tercero como mediador, que generalmente es el lonko o líder tradicional de la comunidad.

Los primeros contactos entre el pueblo mapuche y sistema normativo occidental comenzaron en el siglo XVI, y se fueron consolidando en el siglo XVII cuando se realizaban Parlamentos, que fueron una especie de tregua después de 91 años de guerra, en que los líderes del pueblo mapuche y las autoridades representantes de la corona de España se reunían a dialogar."104 En esta época, los diversos territorios mapuche, se organizaban autónomamente en distintos territorios bajo el liderazgo de autoridades tradicionales, que eran los encargados de parlamentar con los españoles y de dirigir a los integrantes de los lof, ${ }^{105}$ que constituían la base del sistema social, íntimamente relacionados con el sistema económico y jurídico. ${ }^{106}$ Este sistema cambió con la colonización y la instalación del orden jurídico, político y militar en el territorio indígena.

La historiografía nacional ha identificado tres etapas en la relación jurídica entre el Estado de Chile y el pueblo mapuche. La primera, se sitúa entre los años 1810 y 1830 y corresponde al período de la lucha por la independencia, en que los legisladores de la República intentaron asimilar e incluir al mapuche al proyecto nacional; la segunda etapa corresponde a los años 1830 a 1850 en que se retornó a los mecanismos de relaciones fronterizas a través de los parlamentos y una tercera etapa de la ocupación de la Araucanía a través de la fuerza militar, que va desde 1860 hasta la década de 1880, donde se consolida el dominio estatal en territorio indígena y que alcanza su máxima expresión con el establecimiento de reducciones. ${ }^{107}$

Desde 1861, el Estado chileno desarrolla una invasión militar de la Araucanía, ${ }^{108}$ conocida como la 'Pacificación de la Araucanía". En este proceso, el derecho jugó un doble rol dentro de la incursión del Estado chileno en la Araucanía, por un lado, generó instancias de para legitimar la apropiación territorial, y por el otro, impuso un sistema punitivo occidental,

\footnotetext{
${ }^{102}$ ANTONA (2014), p. 431

103 VILLEGAS (2014) pp. 213-247.

104 BENGOA (1996), p. 33

${ }^{105}$ Unidades de parentesco mapuche, donde las autoridades tradicionales ejercen jurisdicción y constituyen la base del sistema social, CEPAL-ATM (2012), p. 28

106 CEPAL-ATM (2012), p. 28.

107 PINTO (2014), p. 67.

${ }^{108}$ Este proceso se perpetúa con la ley del 04 de diciembre de 1866, que continúa regulando la enajenación del territorio indígena, da origen a la Comisión radicadora y a los títulos de Merced, entregando la propiedad de las tierras indígenas al Estado Chileno, facultándolo para enajenar y colonizarlo por chilenos o europeos.
} 
transformándose en un dispositivo de aculturación. ${ }^{109}$ La Provincia de Arauco ahora es considerada 'Territorio de Colonización' y a través de la Ley $\mathrm{N}^{\circ} 4802$, se comienzan a liquidar las propiedades comunitarias mapuche, mediante la creación de Juzgados de Indios ${ }^{110}$ dedicados a dividir las comunidades de indígenas que tengan título de merced: "de este modo, con gestiones y peticiones, las personas mapuches fueron reconfigurando las subdivisiones y limitaciones de sus predios agrícolas, lo que se puede entender como posesiones rurales que previamente les habían sido otorgadas por la Comisión Radicadora". ${ }^{111}$ A partir de un sistema de decretos, se fue regulando el proceso de enajenación de las tierras indígenas, que se incorporaban a la nueva provincia de Arauco. En ellas, los habitantes debían someterse a las leyes de Chile y a la jurisdicción de sus tribunales, los que "legalizaron" la expropiación de tierras y la constitución de la propiedad privada, como un mecanismo de imposición del liberalismo político y económico, bajo el ideal de la civilización y el progreso imperante. ${ }^{112}$ A partir de estas diferencias culturales, se fue tejiendo un vínculo de 'tolerancia represiva' desde el Estado, conforme a la cual el indígena es anormal, "idea que se remonta a las raíces del positivismo criminológico imperante en la primera mitad del siglo XX". ${ }^{113}$

En este contexto, el historiador Daniel Palma constata la existencia de un discurso imperante que exalta la situación de bandidaje rural, para fundamentar la creación de persecución del delito y de instauración de un sistema carcelario al sur del Bío Bío. ${ }^{114}$ Por ello, en 1896 se creó la Gendarmería de Colonias, dirigida por Hernán Trizano que tuvo a su cargo "la vigilancia y seguridad de las colonias nacionales y extranjeras y de los terrenos rematados en todo el territorio de colonización". ${ }^{115}$ En 1892, mediante decreto, se organizaron las guardias que sirven en las diferentes prisiones del territorio de la República, dictándose para estos efectos el "Reglamento para las Guardias Especiales de Prisiones".

Luego, en agosto de 1911, mediante decreto $\mathrm{N}^{\circ} 2140$, se aprueba el "Reglamento Jeneral de Prisiones" y Decreto Supremo N ${ }^{\circ} 3.140$ del año 1965 del Ministerio de Justicia, que aprobó el Reglamento sobre Normas Básicas para la Aplicación de una Política Penitenciaria Nacional, obedeciendo a la necesidad de adecuación de la normativa nacional a los nuevos estándares de protección de derechos de los internos, especialmente a la aprobación de las Reglas Mínimas para el Tratamiento de los Reclusos por parte de la Asamblea General de las Naciones Unidas el año 1955.

\footnotetext{
109 "En forma paralela a la ocupación militar, en la Araucanía se produce una ocupación nominal, a través del derecho, de una sucesión de leyes que van normando un territorio que hasta entonces gozaba de autonomía. Pero no sólo nos encontramos ante textos legales, sino también ante el espíritu que se expresa a través de dichos textos legales, y de las intenciones que se traducen a través de ellos" en CORREA y MELLA (2010), p. 54

${ }^{110}$ MINISTERIO DE TIERRAS Y COLONIZACIÓN, Decreto 411, Artículo $1^{\circ}$ “Créanse 5 Juzgados de Indios que, a petición de parte procederán a dividir las comunidades de Indígenas que tengan título de merced otorgado con arreglo a las leyes de 4 de diciembre de 1866, y posteriores, y a restituir los terrenos comprendidos en dichos títulos, conforme a las disposiciones de la presente ley."

${ }^{111}$ CONTRERAS (2018.), p. 26.

${ }^{112}$ En el ámbito jurídico penal, el choque cultural fue significativo para ambos pueblos. Para el historiador Mario Góngora, se trata, fundamentalmente de 'diferencias culturales de motivación económica, de desnivel entre economías de subsistencia y mentalidad de lucro', en GÓNGORA (1966), passim.

${ }^{113}$ VILLEGAS (2014), passim.

${ }^{114}$ PALMA (2017), núm. 4.

${ }^{115}$ PALMA (2017) p. 118.
} 
En 1998 reformulado por última vez a fines del año 2011 se promulga el Decreto Supremo $\mathrm{N}^{\circ}$ 518, Sobre Reglamento de Establecimientos Penitenciarios. Pese a ser una materia de reserva legal (dado que regula materias de derechos fundamentales), la totalidad del régimen penitenciario se encuentra regulado en un nivel normativo inferior, consagrado a partir del ejercicio de la potestad reglamentaria del poder ejecutivo, evidenciado la falta de un enfoque de derechos en la materia.

Además, es posible vislumbrar que en la reglamentación penitenciaria no existe referencia alguna respecto de las condiciones carcelarias y de los derechos religiosos y culturales de las personas indígenas privadas de libertad. Sin perjuicio de lo anterior, han existido instancias de reconocimiento y ejercicio de los derechos culturales de personas mapuche privadas de libertad, como se expondrá en el apartado siguiente.

\section{Algunas experiencias interculturales en La Araucanía}

La existencia de imputados/as y condenados/as mapuche vinculados al 'conflicto interétnico', contrasta con el déficit que existe en normativa nacional en el ámbito de la regulación de los derechos de las personas indígenas privadas de libertad y a la falta de apego a los estándares internacionales en la materia ${ }^{116}$. Pero, pese a este déficit normativo, las movilizaciones de las autoridades tradicionales mapuche, como fue el caso del Machi Celestino Córdova, o de la Machi Francisca Linconao, han logrado ciertas prerrogativas en los recintos carcelarios, como el acceso a tratamientos interculturales de salud o el agrupamiento en módulos especiales para personas mapuche en los denominados "módulos de comuneros" en las cárceles de Temuco y Angol, que han ido dibujando un derecho penitenciario intercultural, que debe ser reconocido por el ordenamiento jurídico nacional.

La machi Francisca Linconao, ${ }^{117}$ es una de las más connotadas líderes espirituales del mundo mapuche contemporáneo. Fue la primera persona en lograr el reconocimiento del Convenio 169 de la OIT, cuando enunció la violación de un sitio de significación cultural; los denominados "Menokos", humedales donde habitan fuerzas que en la cosmovisión mapuche tienen el carácter de sagrados, y además, la pérdida de plantas medicinales, vitales para su trabajo de machi. Este recurso de protección fue acogido por la Corte de Apelaciones de Temuco, y constituyó la primera vez que se aplicó el Convenio 169 en Chile, reconociendo la obligación del estado de respetar la importancia especial que para las culturas y valores espirituales de los pueblos indígenas reviste su relación con las tierras o territorios. ${ }^{118}$

El año 2016, fue privada de libertad acusada de un delito del cual fue posteriormente absuelta. Para la celebración del We tripantu (año nuevo mapuche) del año 2016, el Tribunal de Garantía de Temuco autorizó el traslado de la Machi Francisca Linconao a su Rewe (sitio sagrado) a efectos de que practicara una ceremonia, ello mientras permanecía en prisión preventiva en el Centro Penitenciario Femenino de Temuco. En este caso, se solicitaba que la Machi pudiera acceder a su Rewe o altar sagrado, con el fin de retomar fuerzas y sanar la

\footnotetext{
${ }^{116}$ INDH (2018), passim.

${ }^{117}$ CAYUQUEO (2017), passim.

${ }^{118}$ Corte de Apelaciones de Temuco. Causa Rol N 1773-2008, sentencia del 16 de septiembre del 2009.
} 


\section{Polít. Crim. Vol. 15, № 29 (Julio 2020), Art. 9, pp. 259-289 [http://politcrim.com/wp-content/uploads/2020/07/Vol15N29A9.pdf]}

enfermedad generada por su privación de libertad. En su oportunidad, Gendarmería Regional evacuó primeramente un informe negativo ${ }^{119}$ al Juzgado de Garantía de Temuco para la realización de esta ceremonia. Sin embargo, con posterioridad, la misma institución informa positivamente a la solicitud de traslado ${ }^{120}$ en los siguientes términos: "[...] ante este nuevo escenario, considerando en particular la cosmovisión de la etnia Mapuche y la figura representativa y autoridad ancestral de la imputada para su comunidad, el respeto a su condición de Machi [...]"; con lo que en definitiva, el Tribunal de Garantía invocó el artículo 8.2 del Convenio 169 de la OIT, y resolvió autorizar a la Machi Francisca Linconao a concurrir a su Rewe y con ello realizó su ceremonia religiosa en el contexto del We tripantu Mapuche.

En otro caso, el día 23 de noviembre de 2017, el comunero mapuche Guido Carihuentro, quien cumplía condena en el Centro de Cumplimiento Penitenciario de Temuco, fue trasladado a su hogar ubicado en la comunidad Huilio, para realizar una ceremonia espiritual en relación con su rol de Zugun Machifeo interprete de Machi, que era necesaria para mejorar su salud. Así también en el denominado "Caso Iglesias ${ }^{121}$ ”, uno de los imputados que más tarde quedaría absuelto, el lonko Alfredo Tralcal, solicitó participar de la ceremonia del gillatun en LLeupeko, Comuna de Padre Las Casas, autorización que fue concedida el 01 de diciembre de 2017, también en base a consideraciones religiosas y culturales.

En estos casos, se entrelaza el derecho a la libertad de culto, con el ejercicio del derecho a la salud. Pero, sin duda, el caso que alcanzó mayor notoriedad fue el del Machi Celestino Córdova $^{122}$, quien requería realizar una renovación de su Rewe, ubicado en su domicilio, situación que constantemente fue denegada, afectando y deteriorando su salud, lo que incluso derivó en el traslado hacia el Hospital Intercultural de Nueva Imperial para ser examinado por otro Machi ${ }^{123}$. La denegación de la visita del Machi Celestino a su Rewe, generó una serie de movilizaciones que derivaron en una prolongada huelga de hambre, debido a la falta de atención a las necesidades espirituales del machi Celestino Córdova por parte de Gendarmería para quienes este tipo de salidas, no se encuentran reguladas dentro del

\footnotetext{
119 Oficio $\mathrm{N}^{\circ}$ 576/2016 de fecha 21 de junio de 2016, Gendarmería señalo: “2.- (...) considerando el escenario que hoy vive la región, la repercusión que podría originar en los familiares de las víctimas, la gravedad del delito por el cual la imputada está cumpliendo la medida cautelar de prisión preventiva, el sector geográfico que se ha solicitado para llevar a cabo la ceremonia en cuestión, y que corresponde a un sector que ha sido foco de múltiples ataques incendiarios y que han concitado atención mediática y de la opinión pública. Considerando además las máximas de las experiencias (sic) sobre la eventual presencia masiva de comunidades Mapuche a esta ceremonia tradicional, comunidades que están involucradas en acciones de presión que se han generado producto de la recuperación territorial y eventualmente podrían ocasionar algún tipo de incidentes difíciles de prever en contra de la integridad física del personal de custodia o de la propia imputada (...)".

${ }^{120}$ Gendarmería de Chile, Oficio $\mathrm{N}^{\circ}$ 1795/2016

${ }^{121}$ Caso de alta connotación pública asociado al conflicto mapuche con el estado y las elites, situación ocurrida el 10 de junio del año 2016, donde fue incendiada la "Iglesia evangélica del Señor" camino Truf Truf, Km 3 Comuna de Padre Las Casas, Ruta S-269. Donde hubieron 4 imputados, 2 de los cuales quedaron absueltos y los restantes hoy cumplen condena.

${ }^{122}$ Condenado por el delito de incendio con resultado de muerte del caso de alta connotación pública conocido como caso 'LuchsingerMackay', a la pena de 18 años de libertad que se encuentra cumpliendo en el CCP de Temuco.

${ }^{123}$ Certificado emitido por Víctor Caniullán Coliñir, Machi del Centro de Medicina Mapuche Ñilawentuwün, del Complejo de Salud Intercultural Hospital de Nueva Imperial, fecha 24 de octubre de 2017.
} 
Reglamento de Establecimientos Penitenciario, por lo tanto se cataloga como salidas especiales de alto riesgo, con resultados difíciles de prever en términos de seguridad". ${ }^{24}$

La demanda del Machi Celestino fue respaldada por el Instituto de Derechos Humanos, organismo que sostuvo que era un derecho fundamental concurrir a la realización de una ceremonia espiritual en condiciones de igualdad y no discriminación, todo ello respaldado en antecedentes de salud emanados del ejercicio de la medicina tradicional mapuche, expedidos por especialistas que trabajan al alero del Estado de Chile, en este caso, el Servicio de Salud Araucanía Sur. Es dable señalar la resolución exenta $N^{\circ} 1373$ de fecha 27 de junio de 2006 del Servicio Salud Araucanía Sur, que aprueba el "Protocolo de Atención De salud con Modelo Intercultural" 125 ordena a los Servicios de Salud, ${ }^{126}$ en cuanto órganos del Estado, que respeten, reconozcan y protejan el sistema de salud de los pueblos originarios y del pueblo mapuche en particular, que son parte de su patrimonio cultural, y que en consecuencia realicen en forma directa e indirecta, acciones de promoción, protección, recuperación de la salud y de rehabilitación de las personas enfermas, encuadradas dentro de lo que es considerado prácticas de salud tradicionales de dichos pueblos.

Finalmente el sábado 28 de junio de 2018 el machi Celestino Córdova es trasladado desde el Hospital Intercultural de Nueva Imperial a su Rewe en la comunidad Chicahual Córdova, luego de la autorización de gendarmería y el Ministerio de Justicia. Se dispuso de 14 horas para realizar la ceremonia, autorizando la presencia de 30 personas que acompañaran la ceremonia colectiva. ${ }^{127}$

Este tipo de experiencias dan cuenta de la posibilidad de realizar actividades vinculadas al ejercicio de los derechos culturales del pueblo mapuche, y de abrir los espacios de ejercicio de la libertad de culto en un plano de igualdad respecto de las religiones occidentales. Asimismo, el respeto por la práctica de la espiritualidad mapuche es también un reconocimiento a la dignidad humana, y a sus derechos más elementales como el derecho a la salud y a la integridad, inherentes a la identidad de quienes son parte de un colectivo, como lo es el pueblo mapuche.

A su vez, el reconocimiento de estos derechos religiosos y culturales constituyen demandas culturales de quienes se encuentran privados/as de libertad, generando dinámicas de reflexión acerca la legitimidad de las demandas de las autoridades espirituales del pueblo mapuche, como el caso de la Machi Francisca Linconao en su momento, o el Machi Celestino Córdova, y que también han permitido generar jurisprudencia en materia penitenciaria que avanza

\footnotetext{
${ }^{124}$ Ordinario $\mathrm{N}^{\circ} 1188 / 18$, de fecha 11 de abril de 2018, remite informe respecto a sentenciado Celestino Córdova Tránsito, a Juzgado de Garantía de Temuco.

${ }^{125}$ DL 2.763 de fecha 11 de Julio de 1979 del Ministerio de Salud en su artículo 4 señala:

Al Ministerio de Salud le corresponderá formular, fijar y controlar las políticas de salud. En consecuencia tendrá, entre otras, las siguientes funciones: $\mathrm{N}^{\circ} 16$.- Formular políticas que permitan incorporar un enfoque de salud intercultural en los programas de salud en aquellas comunas con alta concentración indígena

${ }^{126}$ DS 42 del 2004

127 La Tercera, "Machi Celestino Córdova realiza ceremonia de renovación de su rewe”, en https://www.latercera.com/nacional/noticia/machi-celestino-cordova-trasladado-rewe-realizar-ceremoniaespiritual/260805/
} 


\section{Polít. Crim. Vol. 15, No 29 (Julio 2020), Art. 9, pp. 259-289 \\ [http://politcrim.com/wp-content/uploads/2020/07/Vol15N29A9.pdf]}

hacia el reconocimiento de los derechos culturales de los pueblos indígenas, pero que sigue siendo insuficiente.

\section{A modo de conclusión: Una propuesta de adecuación de la normativa interna a los principios internacionales en la materia.}

En el marco de los estándares del derecho internacional de los Derechos Humanos, y del reconocimiento de los pueblos indígenas como sujetos de derechos colectivos; es necesario poner atención al tratamiento institucional y administrativo que el Estado chileno ejerce a los miembros de pueblos indígenas privados/as de libertad, en especial a sus autoridades tradicionales quienes se encuentran al interior de centros penitenciarios.

Aquellos estándares, operacionalizados mediante algunos instrumentos como la Declaración de las Naciones Unidas de los Derechos de los Pueblos Indígenas y el Convenio $\mathrm{N}^{\mathrm{o}} 169$ de la OIT, dan cuenta de la necesaria consideración de las características sociales y culturales del pueblo al que pertenecen quienes se encuentran privados/as de libertad. Para el caso mapuche, es relevante indagar en los principios, orientaciones y mecanismos de aplicación del AzMapu a fin de poder resguardar los derechos fundamentales de quienes se encuentran bajo la tutela del Estado, haciendo eco también a lo que dispone el Reglamento Penitenciario y la propia Ley de Culto.

La cárcel solo debe limitarse a privar a una persona de su libertad más no de su derecho a ser mapuche y como tal, practicar su espiritualidad. Esta necesidad se refuerza cuando quienes se encuentran privados/as de libertad son alguna autoridad cultural como en el caso de los/as Machi o alguna otra autoridad espiritual.

La necesidad de modificar el reglamento penitenciario, obedece a dos aspectos, el primero es que evidentemente regula materias de derechos fundamentales, contraviniendo el principio de reserva legal y del dominio máximo legal; toda vez que reglamenta materias de derechos fundamentales, y en segundo término, debe modificarse ya que el mismo artículo $4^{\circ}$ de este reglamento, hace un reenvío a los Tratados Internacionales de Derechos Humanos; que necesariamente exigen el cumplimiento de sus estándares y llevan a incorporar aspectos propios de la cultura de los pueblos indígenas, mientras éstos/as se mantengan en su tutela.

Es necesario también recalcar que el Estado se encuentra en una posición de garante respecto de las personas privadas de libertad, responsabilidad que se refuerza cuando quienes se encuentran internos/as en el régimen penitenciario pertenece a colectivos especialmente protegidos por el derecho internacional de los derechos humanos.

En este sentido, caminar hacia la búsqueda de un diálogo intercultural, implica tener en cuenta los siguientes elementos para la discusión: a) Apertura y disposición de un sistema de ejercicio de la libertad de culto desde una perspectiva intercultural; b) Acceso a visitas pertinentes a la realidad sociocultural mapuche de los internos/as; c) Planificación de visitas a centros ceremoniales para autoridades mapuche; d) Protocolo para el cumplimiento de medidas alternativas al encarcelamiento, que propendan a un contacto con el entorno natural; e) Condiciones internas acorde a los derechos culturales de los/as internos/as, en materias 
laborales, de alimentación, y especialmente en relación al ejercicio de las libertades religiosas.

Bajo estas consideraciones proponemos las siguientes modificaciones al reglamento penitenciario:

\begin{tabular}{|c|c|}
\hline $\begin{array}{l}\text { Artículo } 5^{\circ} \text {.- Las normas establecidas en el } \\
\text { presente Reglamento deben ser aplicadas } \\
\text { imparcialmente no pudiendo existir } \\
\text { diferencias de trato fundadas en el nacimiento, } \\
\text { raza, opinión política, creencia religiosa, } \\
\text { condición social o cualesquiera otras } \\
\text { circunstancias. } \\
\text { La Administración Penitenciaria procurará } \\
\text { la realización efectiva de los derechos } \\
\text { humanos compatibles con la condición del } \\
\text { interno. }\end{array}$ & 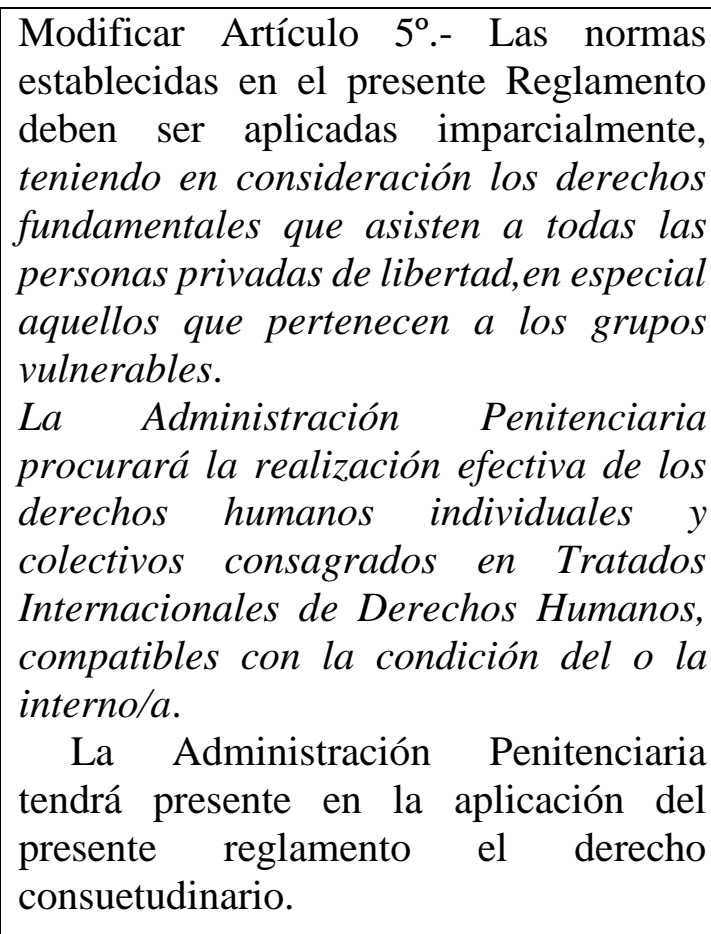 \\
\hline $\begin{array}{l}\text { Artículo } 6^{\circ} .- \text { Ningún interno será sometido a } \\
\text { torturas, a tratos crueles, inhumanos o } \\
\text { degradantes, } \\
\text { palabra u obra, ni será objeto de un rigor } \\
\text { innecesario } \\
\text { en la aplicación de las normas del presente } \\
\text { Reglamento. } \\
\text { Se garantiza la libertad ideológica y } \\
\text { religiosa } \\
\text { de los internos, su derecho al honor, a ser } \\
\text { designados por su propio nombre, a la } \\
\text { intimidad personal, a la información, a la } \\
\text { educación y el acceso a la cultura, procurando } \\
\text { el desarrollo integral de su personalidad, y a } \\
\text { elevar peticiones a las autoridades, en las } \\
\text { condiciones legalmente establecidas. } \\
\text { La Administración Penitenciaria velará por } \\
\text { la vida, integridad y salud de los internos y }\end{array}$ & $\begin{array}{l}\text { Incorporar: } \\
\text { Inc. } 2^{\circ} \text { Se garantiza la libertad ideológica } \\
\text { y religiosa de los internos, y ejercicio de } \\
\text { los derechos culturales consagrados en } \\
\text { los Tratados Internacionales de Derechos } \\
\text { Humanos que se encuentren vigentes, su } \\
\text { derecho al honor, a ser designados } \\
\text { por su nombre social, a la intimidad } \\
\text { personal, a la información, a la educación } \\
\text { con pertinencia cultural, procurando el } \\
\text { desarrollo integral de su personalidad, y } \\
\text { a elevar peticiones a las autoridades, en } \\
\text { las } \\
\text { condiciones legalmente establecidas. }\end{array}$ \\
\hline
\end{tabular}




\begin{tabular}{|l|}
\hline $\begin{array}{l}\text { permitirá el ejercicio de los derechos } \\
\text { compatibles con su situación procesal.[..] }\end{array}$ \\
\hline $\begin{array}{l}\text { Artículo 10.- Los establecimientos } \\
\text { penitenciarios se organizarán conforme a los } \\
\text { siguientes }\end{array}$ \\
principios:
\end{tabular}

a) Una ordenación de la convivencia adecuada a cada tipo de establecimiento, basada en el respeto de los derechos y la exigencia de los deberes de cada persona.

b) El desarrollo de actividades y acciones tendientes a la reinserción social y disminución del compromiso delictivo de los condenados.

c) La asistencia médica, religiosa, social, de instrucción y de trabajo y formación profesional, en condiciones que se asemejen en lo posible a las de la vida libre.

d) Un sistema de vigilancia que garantice la seguridad de los internos, funcionarios, recintos y de toda persona que en el ejercicio de un cargo o en uso de una facultad legal o reglamentaria ingrese a ellos.

e) La recta gestión y administración para el buen funcionamiento de los establecimientos.
Artículo 13.- En la creación de los establecimientos penitenciarios, intervendrán los siguientes criterios orientadores:

a) La edad de las personas que deben ingresar a ellos. b) El sexo de las mismas. c) La naturaleza de las actividades y acciones para la reinserción social que proceda.

d) El tipo de infracción cometida.
Modificar Artículo 10.- Los establecimientos penitenciarios se organizarán conforme a los siguientes principios:

a) Una ordenación de la convivencia adecuada a cada tipo de establecimiento, basada en el respeto de los derechos humanos individuales y colectivos reconocidos por los TDH y la exigencia de los deberes de cada persona.

b) El desarrollo de actividades y acciones tendientes a la reinserción social y disminución del compromiso delictivo de los condenados.

c) La asistencia médica, religiosa, social, de instrucción y de trabajo y formación profesional, todas ellas con pertinencia cultural en condiciones que se asemejen en lo posible a las de la vida libre.

d) Un sistema de vigilancia que garantice la seguridad de los internos, funcionarios, recintos y de toda persona que en el ejercicio de un cargo o en uso de una facultad legal o reglamentaria ingrese a ellos.

e) La recta gestión y administración para el buen funcionamiento de los establecimientos.

Artículo 13.- Agregar letra g)

g) La pertinencia cultural. 
e) El nivel de compromiso delictual de los internos.

f) Las especiales medidas de seguridad o de salud que la situación de ciertos internos haga necesarias.

g) Otros criterios adoptados complementariamente por la Administración Penitenciaria.

Artículo 51.

- Los Alcaides podrán autorizar visitas familiares e íntimas, si las condiciones del establecimiento lo permiten, a los internos que no gocen de permisos de salida y que lo hayan solicitado previamente.

El interno deberá acreditar en su solicitud, la relación de parentesco, conyugal o afectiva, que lo liga con la o las personas que desea que lo visiten.

Las visitas íntimas se concederán una vez al mes y su duración no será inferior a una ni superior a tres horas cada vez. Las visitas familiares se concederán a lo menos dos veces al mes y su duración no será inferior a una ni superior a tres horas cada vez, pudiendo exceder el número de personas, el límite máximo establecido en el artículo 49 del presente Reglamento, lo que será determinado caso a caso, y pudiendo ingresar menores de cualquier edad.
Modificar inc. 1: "Los Alcaides podrán autorizar visitas familiares, intimas y visitas masivas ceremoniales, si las condiciones del establecimiento lo permiten, a los internos que no gocen de permisos de salida y que lo hayan solicitado previamente".

Agregar inc. 4: "En las visitas ceremoniales el interno deberá señalar en su solicitud la ceremonia que desea realizar, indicando sus características y la cantidad de personas a invitar". 


\section{Bibliografía}

AGUILAR, Gonzalo (2015): "El Tribunal Constitucional Chileno frente a la jurisdicción militar", en: Revista de Derecho - Universidad Católica del Norte (vol. 22, n¹), pp. 23-63.

AGUILÓ, Pedro; MILOS, Catalina; NASH, Claudio (2013): Personas privadas de libertad y medidas disciplinarias: análisis y propuestas desde una perspectiva de derechos humanos (Santiago: Centro de Derechos Humanos de la Universidad de Chile).

ALIANZA TERRITORIAL MAPUCHE (2012): Desigualdades territoriales y exclusion social del pueblo mapuche en Chile. Situacion de la Comuna de Ericlla desde un enfoque de derechos (Santiago : CEPAL).

ANTONA, Jesús (2014): "La Declaración Universal de los Derechos Humanos en mapuzungun a la sombra del Az Mapu", en: Revista Española de Antropología Americana (vol. 44, núm. 2).

ATIENZA, Manuel (2013): Podemos hacer más. Otra forma de pensar el derecho (Madrid: Editorial Pasos Perdidos).

AYLWIN, José; MEZA-LOPEHANDIA, Matías; YAÑEZ, Nancy (2013): Los pueblos indígenas y el derecho (Santiago, LOM Ediciones).

RIVERA, Iñaki (2006): La cuestión carcelaria. Historia, Epistemología, Derecho y Política penitenciaria (Barcelona: Ediciones Del Puerto).

BELLO, Carolina; GALLARDO, Andrea; JARA, María José (2005): Reos-obreros y empresarialidad en los talleres carcelarios: un ejemplo de las transformaciones económico-sociales en Chile (1875-1914), Informe de Seminario para optar al Grado de Licenciada en Historia, Santiago: Universidad de Chile.

BENGOA, José (1996): Historia del pueblo Mapuche ( Santiago: Sur Ediciones).

BOROWSKI, Martin (2000): "La restricción de los derechos fundamentales", en: Revista Española de Derecho Constitucional (Año 20. Núm. 59).

BRIONES MARTÍNEZ, Irene (2009): "El uso del velo islámico en Europa. Un conflicto de libertad religiosa y de conciencia", en: Anuario de Derechos Humanos. Nueva Época (Vol. 10), pp.17-82.

BUSTOS, Jesús Antona (2014): "La Declaración Universal de los Derechos Humanos en mapuzungun a la sombra del Az Mapu", en: Revista Española de Antropologia Americana (Vol. 44).

CARNEVALI, Raúl; MALDONADO, Francisco (2013): El tratamiento penitenciario en Chile: Especial atención a problemas de constitucionalidad, en: Ius et Praxis (Vol. 19 $\mathrm{N}^{\circ} 2$ ), pp. 384-418.

CASTRO, Álvaro; CILLERO, Miguel; MERA, Jorge (2010): Derechos Fundamentales de los privados de libertad (Santiago: Ediciones UDP).

CERVANTES, Luis (2009): "Los principios generales sobre la libertad religiosa en la jurisprudencia de los sistemas europeo, interamericano y costarricense de protección de los derechos humanos", en: Sendero. Revista de ciencias religiosas y pastorales (Año $31 \mathrm{~N}^{\circ}$ 93), pp. 271-309

CISTERNAS, Jaime (1997): Historia de la cárcel Penitenciaría de Santiago: 1847-1887, (Santiago: Universidad Catolica de Chile).

CORREA, Martin y MELLA, Eduardo (2010): El territorio mapuche de Malleco: las razones del Illkun (Santiago: LOM Ediciones). 
CORREA, Mario; SALGARRIAGA, Dora (2014): "El epistemicidio indígena latinoamericano. Algunas reflexiones desde el pensamiento crítico decolonial", en: Revista CES DERECHO (Vol. 5 núm. 2), 2014.

DE SOUSA SANTOS, Boaventura (2009): Una epistemología del Sur. La reinvención del conocimiento y la emancipación social (México, Siglo XXI Editores).

DÍAZ, Alejandro; PÉREZ, María Victoria; GONZALEZ, Claudio; SIMON, Jeanne (2004): "Conceptos de enfermedad y sanación en la cosmovisión mapuche e impacto de la cultura occidental", en: Revista Ciencia y enfermería (Vol. 10 núm.1), p. 9-16

DWORKIN, Ronald (2013): Religión sin Dios (Ciudad de México: Fondo de Cultura Económica).

DWORKIN, Ronald (2014): Justicia para Erizos (Buenos Aires: Fondo de Cultura Económica).

ESCOBAR, Ricardo (2017): "El derecho a la libertad religiosa y de cultos en Colombia: evolución en la jurisprudencia constitucional 1991-2015”, en: Revista Prolegómenos Derechos y Valores (20,39), pp.125-138.

FERNÁNDEZ, Marcos (1998): "Relatos de precariedad y encierro. La cárcel rural en Chile en la segunda mitad del siglo XIX", en: Revista de Historia social y de las mentalidades, (Vol. 26), 1998.

FERRAJOLI, Luigi (1999): Derechos y garantías: La ley del más débil (Madrid, Editorial Trotta).

FOUCAULT, Michel (2009): Vigilar y castigar. Nacimiento de la prisión, Madrid: Siglo XXI.

GÓNGORA, Mario (1966): Vagabundaje y sociedad fronteriza en Chile, siglos XVII a XIX (Santiago: Centro de Estudios Socioeconómicos).

GONZÁLEZ, Pablo (2003): "Colonialismo Interno (una redefinición)", en: Revista Rebeldía. (núm. 12), pp. 1-30.

HUICI, Laura (2015): "Laicicidad del Estado y libertad de manifestar la propia religión o creencias: la posición del Comité de Derechos Humanos, el caso de los Sijs en Francia”, en: CAICEDO, Natalia y MOYA, David (Coords.), Diversidad cultural e interpretación de los derechos (Madrid: Centro de Estudios Políticos y Constitucionales).

INDH (2018): Estudio de las condiciones carcelarias en Chile. Diagnóstico del cumplimiento de los estándares internacionales de Derechos Humanos sobre el derecho a la integridad personal (Santiago: Andros).

INDH (2014): Estudio exploratorio. Estado de chile y Pueblo Mapuche: análisis de tendencias en materia de violencia estatal en la Región de la Araucanía (Santiago: INDH).

JACCARD, Danko (2018): Juzgados de Indios: Historia y memoria de la división de Comunidades 1927-1967 (Temuco: Universidad de la Frontera).

LANDER, Edgardo (1993): La colonialidad del saber: eurocentrismo y ciencias sociales. Perspectivas latinoamericanas (Buenos Aires: CLACSO).

LEÓN, Marco Antonio (1998): "Entre el espectáculo y el escarmiento: el presidio ambulante en Chile (1836-1847)", en: Revista de Humanidades y Ciencias sociales ( $\left.\mathrm{N}^{\circ} 43\right)$.

LEÓN, Marco Antonio (2003): Encierro y corrección. La configuración de un sistema de prisiones en Chile (1800-1911) (Santiago: Universidad Central), tomo III. 
LOPERA, Gloria (2006): Principio de proporcionalidad y ley penal (Madrid: Centro de Estudios políticos y constitucionales).

MELIN, Miguel; CURIHUINCA, Elsy; COLIQUEO, Patricio y ROYO, Manuela (2015): Azmapu: una aproximación del sistema normativo desde el derecho propio, (Wallmapu: Rojo Ediciones).

MELIN, Miguel; MANSILLA, Pablo; ROYO, Manuela (2019): Cartografía cultural del Wallmapu. Elementos para descolonizar el mapa en el territorio mapuche, (Santiago: LOM Ediciones).

MELOSSI Darío; PAVARINI Massimo (1980): Cárcel y fábrica. Los orígenes del sistema penitenciario (siglos XVI-XIX) (México: Siglo XXI Editores).

NOGUEIRA, Humberto (2008): Derechos Fundamentales y Garantías Constitucionales, (Santiago: Librotecnia), tomo II.

NOGUEIRA, Humberto (2006): "La libertad de conciencia, la manifestación de creencias y la libertad de culto en el ordenamiento jurídico chileno", en: Ius et Praxis (vol.12, n.2), pp.13-41.

PALOMINO, Ricardo (2009): "Libertad religiosa y libertad de expresión", en: Ius Canonicum, ( XLIX, N. 98), pp. 509-548.

PASTOR, Enrique; TORRES, Manuela (2017): "El sistema penitenciario y las personas privadas de libertad en España desde una perspectiva internacional”, en: Polít. crim. (Vol. 12, No 23), pp. 124-150.

PAUL, Álvaro (2016): "Fernández Martínez contra España: Caso sobre neutralidad religiosa con implicancias para Chile y el sistema interamericano", en: Revista de Derecho de la Universidad Católica del Norte (Vol.23, n¹), pp.269-287.

PINTO, Jorge (2003): La formación del Estado y la Nación y el Pueblo Mapuche. De la inclusión a la exclusión (Santiago: DIBAM).

PINTO, Jorge (2014): Conflictos étnicos, sociales y económicos. Araucanía 1900-2014, (Santiago: Pehuen Editores).

PALMA, Daniel (2017): "Policías rurales en Chile: los Gendarmes de las Colonias (18961907)", en: Claves. Revista de Historia (Vol. 3, núm. 4).

QUIDEL, José (2005): "Pu Mapuche ka pu wigka, chumgechi ñi xokituwün. Las relaciones interétnicas a través de la religión. El caso de los mapuche y no mapuche en Chile", en: Revista anthropos. Huellas del conocimiento (N²07), pp. 153-166

RIVERA, Iñaki (2006): La cuestión carcelaria. Historia, Epistemología, Derecho y Política penitenciaria (Barcelona: Editores Del Puerto).

ROXIN, Claus (1999):Derecho Penal. Fundamentos. La estructura de la teoría del delito. (Madrid: Civitas), tomo I.

SÁNCHEZ CURIHUENTRO, Juan (2001): "El Azmapu o sistema jurídico mapuche”, en: Revista Crea (Año 2, N²) pp. 28-38, 2001.

SÁNCHEZ, Ester (2003): Justicia multicultural y pluralismo jurídico (Bogotá: Universidad Nacional de Colombia).

SIMON, Jonathan (2007): Gobernar a través del delito (Barcelona: Gedisa).

UGARTE, José Luis (2011) "Los derechos en su nueva hora: La teoría externa de los derechos fundamentales", en: Revista de Derecho Universidad Católica del Norte, (vol. 18, n²), pp. 361-373.

VILLEGAS, Myrna (2008): "El derecho penal del enemigo y la criminalización del pueblo mapuche", en VILLEGAS, Myrna (coord.) Contribuciones críticas al sistema penal 
de la post modernidad. Libro Homenaje a Eduardo Novoa Monreal (Santiago: Ediciones Universidad Central), pp. 423-464

VILLEGAS, Myrna (2014): "Sistemas sancionatorios indígenas y derecho penal: ¿Subsiste el az mapu?", en: Política Criminal (Vol. $9 \mathrm{~N}^{\circ} 17$ ), pp. 213-247.

VILLEGAS, Myrna (2018): "Tratamiento jurisprudencial del terrorismo en Chile (19842016)", en: Política Criminal (Vol. 13, N 25).

WOLKMER, Antonio (2006): Pluralismo Jurídico. Fundamentos de una nueva cultura del derecho (Madrid: Editorial MAD). 